\title{
Aproximación al estado del arte sobre comunicación y educación en Colombia*
}

\author{
Elssy Yamile Moreno Pérez ${ }^{* *}$ \\ Recibido: 2017-12-10. Enviado a pares: 2018-01 15. \\ Aprobado por pares: 2018-02-20. Aceptado: 2018-02-28 \\ https://doi.org/10.22395/angr.v17n33al1
}

\begin{abstract}
Resumen
El documento que aquí se presenta se propuso hacer un acercamiento a la producción académica que sobre la relación entre comunicación y educación se realizó en Colombia en el periodo comprendido entre 1991 y 2011. La primera parte corresponde a la identificación de los principales enfoques teóricos y conceptuales trabajados, la segunda a los temas y problemas de interés y la tercera a los ejes centrales sobre los que giraron los trabajos consultados, entre los que se encuentran como fundamentales la cultura, el lenguaje y los códigos. El proceso se desarrolló bajo un enfoque hermenéutico, dado el interés por entender cómo se ha comprendido el objeto "comunicación-educación" en Colombia. En términos metodológicos, se optó por la realización de un estado del arte. Entre las reflexiones más importantes de esta revisión se plantean las dificultades para precisar el lugar epistemológico en el que se ubica la educomunicación, sin embargo, se reconoce que es un campo que se ha construido más desde las prácticas sociales y apuestas ético políticas que desde apuestas teóricas.
\end{abstract}

Palabras clave: educación/comunicación, educomunicación, escuela, cultura, cultura mediática, cultura escolar, lenguajes, códigos, medios en la escuela.

Este documento hace parte de la investigación titulada De la educación/comunicación a la pedagogía/comunicología para optar por el título de doctora en Educación. Corresponde a la etapa inicial del mismo. Es un estado del arte sobre el campo de la educación/comunicación en Colombia, en un periodo comprendido entre 1991 y 2011.

* Elssy Yamile Moreno Pérez, comunicadora social-periodista, magíster en Desarrollo Educativo y Social y candidata a doctora en Educación de la Universidad Pedagógica Nacional de Colombia, docente de la Maestría en Comunicación, Desarrollo y Cambio Social de la Universidad Santo Tomás, Bogotá. elssymoreno@usantotomas.edu.co Orcid: https:// orcid.org/0000-0001-9606-0654 


\title{
Approach to the state of the art on communication and education in Colombia
}

\begin{abstract}
This paper intends to make an approach to the academic production related to the relationship between communication and education that was published in Colombia from 1991 to 2011. The first part comprises the identification of the main theoretical and conceptual approaches addressed in this paper; the second one addresses the issues and problems of interest; and the third one relates to the central axes of the analyzed works, among which the culture, the language, and the codes are fundamental. The research was carried out with a hermeneutical approach, given the interest to understand how the object "communication-education" in Colombia has been understood. In methodological terms, it was decided to make a "state of the art". The difficulties in specifying the epistemological place in which educommunication is located are among the most important reflections of this review. However, it is recognized that this is a field that has been built more from social practices and ethical-political approaches than from theoretical ones.
\end{abstract}

Keywords: education / communication, educommunication, school, culture, media culture, school culture, languages, codes, media at school.

\section{Aproximação ao estado da arte sobre comunicação e educação na Colômbia}

\begin{abstract}
Resumo
O documento que aqui se apresenta propôs-se a fazer uma aproximação à produção acadêmica sobre a relação entre comunicação e educação que se realizou na Colômbia no período compreendido entre 1991 e 2011. A primeira parte corresponde à identificação dos principais enfoques teóricos e conceituais trabalhados, a segunda aos temas e problemas de interesse e a terceira aos eixos centrais sobre os quais giraram os trabalhos consultados, entre os quais se encontram como fundamentais a cultura, a linguagem e os códigos. O processo desenvolveu-se sob um enfoque hermenêutico, dado o interesse por entender como se compreendeu o objeto "comunicação-educação" na Colômbia. Em termos metodológicos, optou-se pela realização de um estado da arte. Entre as reflexões mais importantes dessa revisão apresentam-se as dificuldades para precisar o lugar epistemológico no qual se localiza a educomunicação, no entanto, reconhece-se que é um campo que se construiu mais a partir das práticas sociais e apostas ético-políticas do que a partir de apostas teóricas.

Palavras-chave: educação/comunicação, educomunicação, escola, cultura, cultura midiática, cultura escolar, linguagens, códigos, meios na escola.
\end{abstract}




\section{Introducción}

Este trabajo hace parte de una investigación más grande sobre la relación de orden epistemológico que existe entre pedagogía y comunicología, más que entre educación y comunicación y que corresponde a la tesis de doctorado en Educación que actualmente curso. El estado del arte que aquí se presenta proviene de una investigación documental sobre publicaciones que se inscriben explícitamente en el campo de la educación/comunicación en Colombia, para un periodo de veinte años, comprendidos entre 1991 y 2011. En su elaboración se consultaron cincuenta y siete documentos, entre libros y artículos. Vale la pena aclarar que, si bien son publicaciones hechas en Colombia, sus autores no necesariamente lo son.

La realización de este documento es fundamental en tanto permite ubicar el estado de la discusión en este campo de estudio en el país, teniendo en cuenta cómo se ha abordado el tema, cuáles son los puntos de foco, las inquietudes resueltas o por resolver y las tendencias.

El enfoque bajo el que se construye, por su naturaleza, es hermenéutico. Así mismo, cuando se definió el corpus y se hizo una revisión preliminar del mismo, se elaboró una matriz que permitió seleccionar y registrar la información más relevante de los documentos, con el propósito de establecer una clasificación y análisis transversal, de conjunto. En la matriz se tuvieron en cuenta los siguientes elementos: a) enfoques teóricos y conceptuales desde donde se asume el campo de la educomunicación en Colombia; b) los temas y problemas de interés de los autores; c) las nociones de: cultura, cultura escolar, cultura mediática, lenguaje y técnica; c) el lugar que se le da al sujeto educativo y a las instituciones en los trabajos; y g) reflexiones generales. La estructura del texto corresponde justamente al orden en el que se presentaron los anteriores elementos. Se adjunta también la información sobre el corpus de estudio.

\section{Enfoques teórico-conceptuales}

Es académicamente posible y políticamente deseable que se considere la interrelación entre Comunicación y Educación como un nuevo campo de intervención social y de investigación científica en América Latina. Este reconocimiento significa que ni la comunicación ni la educación han alcanzado aisladamente a atender determinadas necesidades o resolver determinados problemas del 'estar con-en el mundo' y de la construcción de relaciones igualitarias y democráticas entre los seres humanos. (Soares, s.f.)

Esta afirmación de Ismar de Olivera, reúne elementos epistémicos y socio-mediáticos; sin embargo, nos hace pensar que la interrelación entre educación y comunicación aún es incipiente. Es un campo de estudio que está en proceso de construcción, pues desde hace cerca de 50 años se habla del mismo, pero como campo autónomo tiene grandes dificultades y potencialidades. Así mismo, es necesario reconocer que se ha alimentado desde diversas posturas políticas y pedagógicas, pero hay pocos trabajos que se preocupen por la fundamentación epistemológica del mismo. 
En términos generales, puede afirmarse que para algunos (educadores, educandos, comunicadores) aún hoy la relación entre educación y comunicación no es otra cosa que la incursión del medio de comunicación (prensa, radio, televisión e internet) en la escuela, sin importar el sentido de dicha acción. Como bien lo menciona Huergo, los dos fenómenos han sido víctimas de reduccionismos en tanto el primero suele equipararse al medio y el segundo a la escuela, es decir, se ha girado más en torno a las instituciones que a los objetos de conocimiento (Huergo y Fernández, 1999).

En esta misma línea, Mario Kaplún (1985) planteaba que la relación entre educación y comunicación tenía lugar desde tres posturas: a) educación que pone énfasis en los contenidos; b) educación que hace énfasis en los efectos y c) educación que pone énfasis en el proceso. La primera se refiere al modelo tradicional de la comunicación; la segunda se basa en el mismo proceso (emisor-canal-receptor) pero agrega el elemento de la retroalimentación y la tercera se basa, según Kaplún (1985), en la transformación de las personas y de las comunidades, teniendo en cuenta la interacción entre el emisor y el receptor.

A partir de estas concepciones y las de otros autores como Jesús Martín-Barbero y Daniel Prieto Castillo, Pedro Gómez (1999) propone la relación entre comunicación y educación como un proceso de interrelación entre el sujeto y los medios. Consideramos que la postura planteada por Gómez no reconoce ni los otros escenarios educativos ni los procesos comunicativos no mediáticos. Tras la presentación del estado del arte en Colombia se podrá identificar en qué lugar se ubica la producción sobre la relación entre comunicación y educación en el país para, quizá, ampliar la lectura sobre este campo de estudio.

De otro lado, la escuela en Latinoamérica, como institución social, ha sufrido varios procesos que muchos han denominado de crisis. En varios países se cuestiona su carácter conservador de las normas, su contribución al mantenimiento del statu quo en muchas zonas de la región. Muestra de ello es la emergencia (o quizá re-aparición, si se tiene en cuenta la historia de mediados y finales del siglo XX en América Latina) de los movimientos estudiantiles en países como Chile, Argentina o algunos de América Central. En este sentido, no puede desconocerse que la pedagogía cumple un papel fundamental, en tanto se propone repensar las prácticas y los procesos educativos permanentemente y una manera de hacerlo es teniendo en cuenta su relación con la comunicación. Al respecto, Gutiérrez y Prieto mencionan que "buena parte del discurso educativo tradicional es desarrollado de una manera lineal. El discurso pedagógico exige, en cambio, un proceso que avanza en espiral. El tratamiento recurrente parte de la educación como un fenómeno comunicacional, que pide la participación del interlocutor en todos y cada uno de los pasos" (Gutiérrez y Prieto, 1999, pp. 58).

A continuación, el lector encontrará los elementos identificados en el estudio y las reflexiones derivadas del mismo.

En el corpus objeto de este estudio, la discusión sobre la educación se alimenta fundamentalmente de algunos discursos provenientes de la educación popular y la peda- 
gogía crítica, en donde autores como Paulo Freire, Celestín Freinet, Jorge Huergo y Henry Giroux predominan. Así mismo, el discurso sobre el papel determinante de la técnica en los procesos educativos es imperante. Los autores de manera reiterada cuestionan el sentido de la educación y el papel de la escuela, sus cambios, sus maneras de funcionar, sus contenidos (fragmentados, disciplinares, descontextualizados), sus didácticas, sus formas de evaluación y sus conexiones con los medios de comunicación.

En la mayoría de los textos, pese a que enuncian el foco de trabajo en el campo profesional de la educación y la comunicación, se hace un énfasis en los medios de comunicación y su manera de asumirlos. En este sentido, el lugar común está orientado hacia la crítica al modelo informacional de la comunicación o de Shannon y Weaver, que, bien se sabe, es de carácter transmisionista y que ellos mismos definían como un "modelo general de la comunicación" aclarando que el término comunicación era entendido desde leyes matemáticas que rigen la transmisión y el procesamiento de la información.

En los documentos estudiados no se ve un interés particular en explicitar a qué tipo de comunicación ni a qué tipo de escuela se refieren. Sin embargo, en algunos casos se enuncian los lugares de partida. Algunas de estas nociones asumen la comunicación como un fenómeno esencial de la vida contemporánea, dada su importancia en la conformación de los procesos sociales (Bustamante, 2006); o como un proceso continuo de exploración, diseño, conocimiento, y codificación de la realidad y de su entorno, realizado por los diversos actores sociales, con el propósito de actuar estratégica y coordinadamente para transformarla (CAR, Alto Magdalena, 2002). Otros se centran en su condición dialógica, según la cual:

El diálogo no sólo se refiere a la comunicación verbal, cara a cara, sino que involucra otras formas de comunicación. En la medida en que no propende exclusivamente por la unidad de los contrarios reconciliados, sino que encarna en la lucha constante, un movimiento de confrontación de ideas; el diálogo es también una fuente de creatividad social. (Castellanos, 2005, p. 22).

Sobre la comunicación en la escuela o en el aula, son más escasos los desarrollos. Algunos trabajos se orientan hacia: a) la diferenciación de estilos lingüísticos y géneros discursivos entre docente y estudiante (Uribe y Hederich, 2007); b) el análisis sistemático del currículo en medio de las tensiones entre lo que los autores denominan cultura escolar y cultura mediática (Rodríguez, 2005) y c) la comunicación para la educación entendida como un esfuerzo en el sentido de escolarizar la comunicación o tecnificar la educación (Huergo y Fernández, 1999).

En términos de tendencias, puede decirse que aparecen cuatro. Inicialmente, puede hablarse del uso pedagógico de los medios, esta es una mirada que reconoce las posibilidades de relación entre estos y las audiencias. Aquí aparecen dos vertientes: la primera, retomando a autores como Guillermo Orozco y Mario Kaplún (1985), tiene como propósito fundamental apostarle a la formación de públicos activos, que conozcan la estructura del medio, que estén en capacidad de plantear miradas críticas frente a estos (como industrias culturales) y frente a sus contenidos. Aquí se incluye la educación para la recepción, que 
tiene un tinte más politizado, pues busca pensar los medios y las industrias culturales como matrices que visibilizaban tanto actores como estrategias del poder social.

La segunda, que se alimenta de autores como Paulo Freire, le apunta a lo que él denominó "alfabetización para los medios", que asume al medio como forma de expresión y comunicación en un contexto socio-cultural determinado. En la misma línea, Francisco Gutiérrez plantea que "la pedagogía de la comunicación como sistema de análisis de la realidad, lleva al hombre a enfrentarse ante el objeto, no como espectador que descubre elementos de la realidad y ni siquiera como transformador que se enfrenta a la realidad, sino como formando parte integrante de esa realidad" (Gutiérrez, 1995, p. 11-19). Desde esta perspectiva, la relación entre el medio y la audiencia abre oportunidades para ampliar los marcos de interpretación sobre el contexto.

Otra postura es denominada medios para la enseñanza o medios educativos. En este apartado se habla de ejemplos como el de las escuelas radiofónicas, que se dedicaban exclusivamente al ejercicio de la enseñanza a campesinos, para el caso de Colombia con la ACPO (Acción Cultural Popular), o a aquellas experiencias en escuela, cuando el medio no solo se veía como vehículo de información sino como instrumento de comunicación al servicio de los estudiantes, de su proceso de aprendizaje. En esta apuesta, la mirada didactista es la que predomina o, si se quiere, se hace la pregunta por cómo el medio puede contribuir al desarrollo exitoso de procesos de enseñanza-aprendizaje, especialmente en contextos en los que la escuela tradicional no tiene suficiente cobertura.

Para otros autores, los medios son considerados instrumentos de desarrollo, que tienen un potencial transformador, es decir, que se supera el hecho mismo de la relación con el medio, de la existencia de un público activo y crítico, y se abre la posibilidad de emplear el medio para comprender pero también para incidir en la transformación de prácticas culturales concretas; se piensa entonces en un público propositivo. Aquí el desarrollo es visto como un proceso de cambio, de mejoramiento de las condiciones de vida de los sujetos que le apunta al reconocimiento individual y social y para logarlo se usan los medios como dinamizadores de los procesos.

En cuanto a la comprensión de la relación entre la educación y la comunicación, esta es asumida como campo profesional, y se enuncia que se constituye desde la articulación entre una y otra. Aunque parece simple, las implicaciones y condiciones de tal articulación en realidad no han sido asibles con facilidad. La mayoría de los autores reconocen, explicitan el valor y potencial de la interrelación entre los dos campos (educación-comunicación), pero con dificultad se evidencia su complejidad, su densidad, tal como lo expresan Espitia y Valderrama (2009, p. 165). En este sentido, los autores coinciden en afirmar que el campo es joven, que carga con el lastre que cada campo tiene, de manera individual, y ocasionalmente se plantea una discusión en torno a la fragmentación disciplinaria que limita las formas de comprensión integral de los fenómenos sociales, dado el aislamiento. 
Autores como Huergo y Martín-Barbero hacen evidente la dificultad para construir saberes de orden interdisciplinario. Pese a lo anterior, algunos autores se atreven a enunciar su postura frente al tema, como se verá a continuación.

Huergo y Fernández (1999, p. 30) plantearon que:

El campo de la "comunicación y educación, [debe ser] comprendido como proceso donde cada grupo organiza su identidad en el interjuego entre hibridación y permanencia. No sólo puede entenderse como un objeto constituido, sino principalmente como un objetivo a lograr; objetivo que conjuga deseo e interés crítico, que da sentido a las prácticas sociales y culturales.

Esta afirmación ubica la relación entre comunicación y educación en el lugar de lo social y lleva a suponer que las prácticas sociales y culturales adquieren cierto sentido (emancipatorio) solo cuando esta relación tiene lugar; como se evidencia, se ubica la relación en el escenario ético-político, no necesariamente teórico.

Valderrama comparte lo expuesto por Huergo, pero también reconoce posturas como la de Trilla, quien:

Hace una distinción entre la comunicación educativa formal y la comunicación educativa informal. La primera, afirma, parte de un propósito pedagógico y se estructura como procedimiento específicamente educativo. La comunicación educativa informal es aquella que, sin tener una intencionalidad pedagógica y siendo de carácter simple y espontáneo, genera efectos educativos. (Valderrama, 2004, p. 89).

Vale la pena tener en cuenta que la lectura sobre lo formal y lo informal, de lo que el autor denomina comunicación educativa, tiene aparejadas dos estructuras, una didáctica y una narrativa, que, por naturaleza tienen propósitos distintos, uno es de carácter pedagógico que busca enseñar ideas y conceptos y el otro busca entretener. Así mismo, estas acepciones generan consecuencias en el concepto mismo de comunicación, puesto que se le asigna un carácter de formalidad e informalidad al mismo dependiendo del espacio en el que tiene lugar, además, como concepto y como práctica concreta, la comunicación es una sola en tanto específicamente humana, quizá los contenidos o la lengua cambien según el escenario, pero la comunicación no.

Fuentes Navarro (2003, p. 26) afirma que la "educomunicación es toda acción comunicativa en espacios educativos [quizá escolares], realizada con el objetivo de producir o desarrollar ecosistemas comunicativos". En primera instancia, esta definición considera a la educomunicación como acción, lo que la hace difusa. En segunda, el uso del concepto de "ecosistema" empleado anteriormente por Martín-Barbero (1999) es ciertamente problemático, porque se refiere a una comunicación mediatizada en la que:

La escuela debe interactuar, no tanto con los medios, debe interactuar a través de ellos con los «nuevos campos de experiencia» en que hoy se procesan los cambios, es decir, las hibridaciones entre ciencia y arte, entre cultura escrita y audiovisual, y la reorganización de los saberes en los flujos y redes por los que hoy se moviliza la información, el trabajo, la creatividad." (Martín-Barbero, 1999, p.15). 
Desde la teoría de los campos, ciencia y arte corresponden a dos campos distintos, así mismo, cultura alfabética y cultura oral-icónica (Brunner, 1988) también tienen una naturaleza diferente. Una cosa es que puedan darse en el mismo momento histórico y otra es que correspondan a una misma matriz cultural. El otro concepto problemático es el de "ecosistema", que tiene su origen en la media ecology trabajada por McLuhan (1967) y Postman (1970), quienes fueron precursores de la inserción del concepto de ecología en relación con la mediología: "según McLuhan, los medios modelan las percepciones de los sujetos: los seres humanos crean instrumentos de comunicación, pero, en un segundo momento, estos mismos medios les modelan la percepción y cognición sin que sean realmente conscientes de este proceso" (Scolari, 2015, p. 1032). Según lo expuesto en esta investigación, los medios no producen la cultura, por lo tanto, estos planteamientos son considerados deterministas respecto a su lectura de la tecnología.

Hablar de comunicación es hablar de una característica propia de la condición humana, no de la naturaleza en general, por lo tanto, el concepto de ecosistema aplicado a las relaciones sociales y a los procesos de comunicación es discutible, o por lo menos debiera ser más matizado y, aunque como campo de tensiones tiene unas prácticas culturales y sociales y específicas formas de interdependencia, se requeriría mayor claridad y quizá especificidad en el uso y comprensión de esta metáfora.

Soares, por su parte, sostiene que "efectivamente, la interrelación comunicación/ educación es un nuevo campo de conocimiento, que está formado, tiene autonomía y se encuentra en proceso de consolidación" (citado por Valderrama, 2000, p.38). Pero, la mayoría de los hallazgos se dirigen a la formación y consolidación del campo profesional, pero no necesariamente al campo de conocimiento, en tanto la discusión sobre lo que corresponde o no a la interdisciplina aún no está desarrollada.

\section{Temas y problemas de interés}

En la mayoría de los textos se expone una tensión permanente entre el ser y el deber ser de la educación (casi siempre reducida a la escuela) y de la comunicación (casi siempre reducida a los medios). La mayoría de los autores tienden a hacer reflexiones ético-políticas, que evidencian su interés en pensar la escuela como un lugar no para conservar y transmitir conocimiento, sino para abrir espacios en los que se generen cambios que permitan a los sujetos el paso a condiciones de vida cada vez mejores, más dignas. Sin embargo, resulta paradójico que para ingresar a la discusión sobre la relación entre educación y comunicación suele acudirse al lugar de los medios de comunicación en la escuela y no a las dinámicas de comunicación en la misma:

Vivimos en un entorno de información que recubre y entremezcla saberes múltiples y formas muy diversas de aprender, a la vez que se halla fuertemente descentrado por relación al sistema educativo que aún nos rige, organizado en torno a la escuela y el libro (...). La escuela está dejando de ser el único lugar de legitimación del saber ya que hay una multiplicidad de saberes que circulan por otros canales, difusos y descentralizados. Esta diversificación y difusión del 
saber, por fuera de la escuela, es uno de los retos más fuertes que el mundo de la comunicación le plantea al sistema educativo. (Martín-Barbero, 2009, pp. 184).

En primer lugar, habría que preguntarse si el concepto de "mundo de la comunicación" empleado por Martín-Barbero se refiere a los estudios sobre la comunicación o a los medios de información, lo que genera cierta confusión. Además, la escuela es también un mundo de comunicación, la comunicación no es externa a ella, es parte de sus dinámicas. En segundo lugar, surge también el debate sobre viejas y nuevas formas de aprender, la pregunta sería si, en esencia, cambian las formas de aprender o solo cambian los medios y las herramientas tecnológicas. Esto significa que aparece una lectura de los medios como lógica. Se supone entonces que con la llegada de los medios de comunicación se modifican las relaciones entre escuela y entorno, sin embargo, la cultura mediática no necesariamente llega a la escuela a través del medio de información, sino desde los sujetos, por lo tanto los cambios no tienen que ver únicamente con las técnicas sino, fundamentalmente, con la cultura de los sujetos escolares. Es decir, prevalece una preocupación de orden técnico, pero hay cambios y permanencias en los grupos sociales, en su cultura. Lo que permanece es lo estructural de la escuela como institución, así haya incorporación de técnicas nuevas. En los trabajos no suelen identificarse las continuidades, sino las rupturas, lo que dificulta hacer una lectura que conecte los elementos que se exponen.

Aparece también el tema de la ciudadanía. En varios de ellos hay una preocupación por comprender el ejercicio de la ciudadanía o por generar nuevas formas de esta que impliquen cambios en las dinámicas culturales-comunicativas de la escuela. Así, algunos trabajos abordan temáticas como la diversidad, el respeto a la diferencia (por ejemplo de género); a otros autores les interesa la comprensión del conflicto en la escuela (aunque no se hace una diferenciación certera entre los tipos de conflictos que allí transitan, tales como el institucional, el interpersonal, el territorial, etc.), y otros centran sus trabajos en la comprensión de formas de poder, de participación, de reconocimiento de la diversidad y la identificación de formas de relación entre la ciudad (como espacio físico y simbólico, de convivencia) y sus habitantes. Se evidencian entonces preocupaciones por atender problemáticas de orden ético y político. La confusión aparece cuando se plantean soluciones técnicas o mediáticas para resolver las mismas.

En algunos trabajos, incluso, se habla de la educación ciudadana "entendida como la participación y expresión de la comunidad, y de innovación cultural que busca, en la experimentación del lenguaje audiovisual, catalizar los nuevos modos de ver y oír, de leer y narrar" (Matín-Barbero, 1996, p. 12), en otros, términos, nuevas formas de percibir.

Huergo y Fernández (1999) se sitúan en la relación entre prácticas culturales y construcción de ciudadanía. Así, el sentido de los estudios se orienta hacia la identificación, comprensión e, incluso, generación de prácticas culturales que dinamicen el ejercicio de la ciudadanía, en medio de la diferencia y de las particularidades socio-históricas de cada contexto. 
En términos generales, en las posturas asumidas en la mayoría de los documentos que constituyen el corpus de este estudio se hace un énfasis particular en el uso de los medios en entornos escolares, bien sea para generar o afianzar procesos de enseñanza-aprendizaje, en los que se hacen construcciones mediáticas sobre el conocimiento o bien, para referirse a prácticas culturales y procesos sociales permeados por ideologías emancipatorias. El campo de la educación y la comunicación no puede desconocer, ni la existencia de los medios, ni sus implicaciones en las maneras de actuar de los sujetos, en las formas de organizar el trabajo y las relaciones sociales. En últimas, en la manera en que la sociedad hace uso de estos medios. Aunque se asumen varias posturas a la hora de comprender-emplear los medios, pareciese que se reduce el fenómeno de la comunicación humana a la existencia e incidencia de los medios de comunicación, como técnica, en la vida de la escuela. En este sentido, se les atribuyen a los medios facultades técnicas, pero también poderes sobre los grupos sociales, es decir, responsabilidades sobre lo cognitivo y lo ético-político.

A la hora de identificar las preguntas presentes en las discusiones contenidas en los trabajos estudiados, resulta interesante ver cuáles son las más reiterativas. Estas son: a) ¿cómo se concibe el campo de la educación-comunicación?; b) ¿cómo lograr que la escuela sea un espacio que facilite las condiciones para respetar las diferencias y dinamizar el ejercicio de la ciudadanía?; c) ¿qué tipo de sujetos está formando la escuela tradicional? y desde este lugar, ¿cómo contribuir a formar sujetos pedagógicos activos?, d) ¿̇uáles son los elementos conceptuales, metodológicos y prácticos requeridos para la incorporación, uso y apropiación de los medios en contextos escolares?

Estas preguntas evidentemente tienen que ver con los orígenes del campo, con las recientes construcciones al respecto y, probablemente, con la dificultad de separar una y otra cultura (escolar y mediática) de las instituciones en que tienen lugar preferente (escuela-medios). Así mismo, hacen un énfasis especial en las dudas, preocupaciones, debates y retos suscitados por la existencia de los medios de comunicación en las realidades de la escuela. Interrogantes referidos al uso de los medios, al lugar de los sujetos y al papel de los medios y la escuela frente a la discriminación social.

Con menor frecuencia, pero aparecen, interrogantes como estos: a) ¿cómo superar la educación para los medios y llegar a instalar la comunicación como un eje central de los procesos educativos? Vale la pena preguntarse si no está ya instalada, en tanto la comunicación es condición humana, lo que haría suponer cierta asimilación comunicaciónmedio; b) ¿cuáles son los retos epistemológicos y culturales que plantea la presencia de los medios de comunicación en la escuela?; c) ¿cuáles son entonces, esos sistemas sintácticos y semánticos que componen lo que podemos llamar cultura massmediática?, ¿cuáles los de la cultura escolar? (Narváez, 2004 p. 80). Estas cuatro preguntas cambian la dirección de las discusiones, puesto que ya no se centran en la relación escuela-medio, sino en la relación entre educación, comunicación y cultura. Aquí se agregaría, entonces, que cultura escolar y cultura mediática tienen códigos particulares, que no se trata solo de llevar nuevas herramientas tecnológicas a la escuela para dinamizar los procesos de 
enseñanza o el ejercicio de la ciudadanía. Se trata entonces de entender cada cultura, sus particularidades, su gramática y los puntos de cercanía y alejamiento entre las dos. El desarrollo de esta línea de trabajo es más reciente y menos explorado.

Soares plantea, quizá a manera de Resumen, lo que ha sido el centro o los centros de trabajo de la denominada educomunicación, la cual:

Se consolida como campo de diálogo que moviliza grandes estructuras. Identifica cuatro movimientos que se articulan para garantizar su especificidad: la recepción calificada, la educación popular, la articulación colectiva para el cambio social y, a partir de años recientes, el reconocimiento de la educomunicación como derecho de todos alcanzado tanto mediante acciones de un sinnúmero de organizaciones no gubernamentales que la asumen como metodología de acción, como mediante planes globales de políticas públicas. (2009, p.194).

Es decir, desde este postulado, la educomunicación se ha desarrollado más en las arenas de las prácticas sociales que en el orden de lo epistémico.

\section{La cultura, las culturas: entre la cultura escolar y la cultura mediática}

En pocos casos se enuncia una noción precisa de cultura, dado que en la mayoría de los documentos se habla con más frecuencia, tanto de cultura escolar como de cultura mediática. En términos generales, la cultura se asume como parte fundamental del proceso educativo, como elemento esencial del sistema social, no solo como "espacio de creación de sentidos y significados, sino una arena de conflicto para controlar y contribuir a la circulación social de usos y significados, conocimientos, placeres y valores" (Orozco, 1996, p. 8).

En un solo caso, el autor realiza una clasificación de cultura que puede resultar interesante a la hora de hacer la diferenciación entre cultura escolar y cultura mediática:

[Denomina] postfigurativa a aquella cultura en la que el pasado de los adultos es el futuro de cada nueva generación, de manera que el futuro de los niños está ya entero plasmado en el pasado de los abuelos, pues la esencia de esa cultura reside en el convencimiento de que la forma de vida y de saber de los viejos son inmutables e imperecederos. Cofigurativa denomina un tipo de cultura en la que el modelo de vida lo constituye la conducta de los contemporáneos, lo que implica que el comportamiento de los jóvenes podrá diferir en algunos aspectos del de sus abuelos y de sus padres. Finalmente, la cultura prefigurativa es aquella en que los pares reemplazan a los padres instaurando una ruptura generacional, que es la que vivimos hoy, sin parangón en la historia, pues señala no un cambio de viejos contenidos en nuevas formas o viceversa, sino un cambio en la naturaleza del proceso: la aparición de una "comunidad mundial" en la que hombres de tradiciones culturales muy diversas emigran en el tiempo, "inmigrantes que llegan a una nueva era: algunos como refugiados y otros como proscritos", pero todos compartiendo las "mismas leyendas" y sin modelos para el futuro. (Martín-Barbero, 1996, p. 23). 
O en palabras de Margaret Mead (1971, p.35), "en la cultura postfigurativa los niños aprenden primordialmente de sus mayores, en la cofigurativa, tanto los niños como los adultos aprenden de sus pares y en la prefigurativa los adultos también aprenden de los niños".

La cultura escolar es asumida como aquella que tiene lugar en el aula de clase y que comúnmente está supeditada a los procesos de disciplinamiento social de los sujetos, bajo la idea de escolarización (reglas y normas planteadas por la institución y el sistema escolar) o como la forma en la que la escuela se ha estancado en sus procedimientos (Ceballos y Marín, 2003). Varios autores han contribuido a construir esta noción, en tanto reconocen los orígenes de la misma, la manera como está constituida y las implicaciones para la educación y la comunicación.

En cuanto a los orígenes, Valderrama (2000, p. XII), desde una perspectiva ética, plantea una disputa entre las relaciones de verticalidad y horizontalidad existentes entre maestro y alumno:

La comunicación en la educación se ha centrado más en las dinámicas comunicativas que subyacen en la relación pedagógica, en la interacción de los actores del proceso enseñanza-aprendizaje, tanto dentro como fuera de la institución escolar. Ricardo Nassif en los años sesenta quiso modelar la relación pedagógica en términos de la teoría de la comunicación. Esta modelización consistió en asimilar mecánicamente al emisor con el maestro, el mensaje con el saber, el canal con los medios y el receptor con el alumno. La pedagogía de la comunicación hizo algunas críticas a esa modelización como la necesidad de adecuar los conceptos de información y comunicación a la cualidad educativa. Bajo la influencia de ver al receptor-estudiante como un sistema de 'transformación autoestructurante y autoconstructivo' que posee categorizaciones, percepciones y experiencias previas al acto de enseñanza-aprendizaje y que es capaz de producir una 'resultante' que lo autoalimentaría. La comunicación en la educación pretendería conectar científica, funcional y profesionalmente la educación, la tecnología y la comunicación.

Adicionalmente, se hacen evidentes las tensiones a que se enfrenta la escuela, dado el entrecruzamiento con las otras culturas que transitan en el espacio escolar, tales como la mediática o la social.

De otro lado, en lo referido a la manera en que está constituida, Narváez, desde el punto de vista cognitivo, considera que la cultura escolar se estructura a partir de:

La acumulación de la tradición lógico-racional propia de Occidente, sus contenidos básicos son la reflexión lógico-racional, explicaciones que puedan ser cuantificables, categorías y conceptos clasificatorios que permitan agrupar los fenómenos empíricos y los contenidos intelectuales que implican una cierta domesticación de la mente. Los mecanismos de identificación con esta cultura no pueden ser espontáneos, sino aprendidos de manera sistemática y especializada. (2004 p. 104). 
Teniendo en cuenta lo enunciado, la manera de comprender y ejercer el poder es determinante en este tipo de cultura, puesto que genera una serie de condicionantes para moldear el carácter y la conducta de los sujetos. Alude, entonces, a:

Un conjunto de prácticas, saberes y representaciones producidas y reproducidas a partir de la institución escolar. Pero también incluye las modalidades de comunicación y transmisión de saberes para poder actuar socialmente (más allá de la escuela) que operan de acuerdo con la «lógica» escolar. En este sentido, la cultura escolar es una forma de producción, transmisión y reproducción que tiende a la organización racional de la vida social cotidiana. La cultura escolar, entonces, transforma desde dentro la cotidianidad social, imprimiendo en ella formas de distribución, disciplinamiento y control de prácticas, saberes y representaciones aún más allá de los ámbitos identificados como la «institución escolar». (Huergo y Fernández, 1999, p. 47).

Vale la pena preguntarse cuál es lugar que le otorgan al concepto de reproducción, que por demás, es constante en Bourdieu, Freire y en las pedagogías críticas. Así mismo, no es claro si lo cognitivo está incluido allí, cuando hablan de los saberes y las representaciones.

La concepción de cultura mediática se asocia, entre los investigadores, con la supuesta capacidad moldeadora que tienen los medios masivos de comunicación sobre las prácticas culturales, las representaciones sociales y los saberes adquiridos/construidos por los sujetos. Así mismo, se cuestiona su cercanía con los modelos económicos y las industrias puesto que facilita la fragmentación y especialización en cuanto al mercado, el trabajo y el consumo.

De otro lado, Narváez plantea que:

La cultura mediática y su universo semántico, es más cercano a la cotidianidad, al sentido común, y resulta, por fuerza, que su contenido tiene que estar constituido aproximadamente por los siguientes elementos: lo mítico, es decir, las explicaciones sobrenaturales de los fenómenos naturales, sociales y personales, lo imaginario, lo afectivo y lo lúdico. Esta es una cultura cuyo aprendizaje es básicamente imitativo. (2013, p. 85).

Esta es entonces una cultura que cuenta con una estructura fundamentalmente oralicónica, de hecho, al respecto algunos autores consideran que "ha contribuido a poner en crisis la lógica centrada en la escritura y la lectura, dando paso a la denominada 'hegemonía audiovisual'” (Fernández y Huergo, 1999 p. 50); sin embargo, en estricto sentido la tradición oral-icónica es más antigua. Así mismo, dado el carácter masivo, imitativo y la facilidad para acceder a los contenidos, los medios nacionales y transnacionales (como institución, como empresa) persiguen intereses específicos y logran sus principales funciones: la persuasión frente al consumo y la construcción de opinión pública, que suele ser homogenizada; mirada que se ubica en la escuela funcionalista de la comunicación (Narváez, 2013).

Algunos autores consideran que los medios de comunicación y las nuevas tecnologías han generado cambios en la cultura (Huergo y Fernández, 1999 p. 162). En otras palabras, 
que la técnica ha producido cambios culturales, por ejemplo, que los medios han definido aquello que denominamos cultura urbana:

La cultura urbana se ha ido transformando poco a poco en una cultura mediática. Son los medios de comunicación los que van delineando el tipo de cultura a la que denominamos urbana. Hay una relación reciproca entre la determinación de lo urbano ligado al sistema de medios de comunicación y el contenido de los medios de comunicación enraizado en una matriz urbana. Los medios sirven a la ciudad y perfilan de algún modo su cultura, pero la ciudad determina también la especificidad de los medios. A través de los medios masivos es como se traslada esa identidad cultural al resto de la ciudad. (Ceballos y Marín, 2003, p. 13).

Valdría la pena preguntarse si es la cultura y no la técnica la que da lugar a esos cambios, incluso tecnológicos, y preguntarse también cuál es la relación entre urbanización y mediatización.

En un solo caso se habla de una noción distinta de cultura mediática: esta se asume como la "cultura de sujetos más creativos, más innovadores, a partir de una educación centrada en la concepción del diseño y de la tecnología que además puede entrar a reivindicar el papel de la educación en el desarrollo y progreso social y productivo de un país" (Vargas y Rueda, 1996, p.10). Aunque difiere de las anteriores, plantea una mezcla entre lo estético, lo técnico, lo económico y lo político; no es claro el lugar de lo cognitivo. Así mismo, reconoce el potencial de los medios como técnica en los procesos de enseñanza y guarda cierta cercanía con la ideología del progreso y se desconocen las particularidades de la cultura escolar enunciadas con anterioridad.

\section{Lenguajes y códigos}

En el campo de la educación y la comunicación es ineludible la discusión sobre el lenguaje. Algunos autores afirman que "la comunicación y educación son procesos simbólicos, mediados primariamente por el lenguaje, constitutivos básicos de las tramas culturales que les dan forma específica, desde un tiempo y lugar determinados, a las relaciones del hombre con el mundo" (Fuentes, 2003, p. 26).

En los documentos objeto de este estudio, aparece un sinnúmero de apartados en donde se menciona el lenguaje o los lenguajes, aludiendo a diferentes usos, en algunos casos, sin hacer distinciones. Sin que sea el centro del campo, es un elemento fundamental del mismo, por ello se hace necesario mencionar que en varias ocasiones se habla de lenguaje, idioma, código, lenguaje audiovisual, lenguaje radiofónico, lenguaje del medio, entre otros, de manera arbitraria:

Sistemas de símbolos y códigos constituyen los 'idiomas' usados y desarrollados por los medios. Estas formas y sistemas se diferencian comúnmente de los utilizados por las personas en su comunicación cotidiana. Niños, jóvenes y adultos están expuestos constantemente al lenguaje de la televisión, del vídeo, de la informática, del cine, de los out-doors y de los periódicos. Dominar esos 
lenguajes y sus mecanismos de producción, comprendiendo el subtexto de los mensajes vehiculados, conseguir identificar condicionamientos implícitos, revelando el real sentido de lo que es comunicado, es una dimensión de lectura crítica y condición necesaria para una educación transformadora. (Gravis, 1999, p. 60).

Asbel López (1990) hace una precisión conceptual, y manifiesta que no es correcto hablar del lenguaje del medio, como si cada uno de ellos tuviese uno diferente, dado que en esencia el lenguaje como manera particular de expresarse el pensamiento es el mismo con o sin medios. Como diría Martín-Barbero (2003, p. 31), "el lenguaje es la instancia en que emergen mundo y hombre a la vez. Y aprender a hablar es aprender a decir el mundo, a decirlo con otros, desde la experiencia de habitante de la tierra, una experiencia acumulada a través de los signos".

López (1990) considera que es más preciso hablar de retórica del medio, que se refiere a la eficacia en la construcción del mensaje, dada la especificidad de los códigos o normas que regulan la producción en cada medio o, como afirma Benavides:

Los códigos mediáticos son específicos, aunque lo lingüístico sea ineludible, y sus mensajes son perdurables en el tiempo, pueden almacenarse, registrarse en una temporalidad atravesada por dos ejes: se repiten o pueden reproducirse a otro ritmo, como lo que ocurre con la cámara lenta; y se convierten en memoria social, 'en parte de la historia'. (1999, p. 22).

En el corpus de análisis, con frecuencia se emplean expresiones como "lenguaje audiovisual", y se plantea que en la escuela de hoy se carece de formación para comprender dicho "lenguaje", lo que, según expresan los autores, aumenta las distancias generacionales y las posibilidades de trabajo en el aula. Así mismo, se afirma que este (el lenguaje audiovisual) "no ha adquirido suficiente protagonismo en las que llamamos dinámicas comunicativas formales en el ámbito escolar y físicamente en el aula de clase" (Valderrama, 2004, p. 137). Es decir, el trabajo desarrollado por los docentes en el espacio escolar, referido al uso de medios audiovisuales, aún es limitado, lo que sugiere un desaprovechamiento del medio y una confusión entre cultura y técnica.

Al respecto Narváez afirma que:

A los objetos de investigación nacidos del campo del poder y no del campo académico Charlot (2008) les llama 'objetos socio-mediáticos', por oposición a los objetos teóricos. A nuestro juicio, la educomunicación es uno de esos objetos, el cual nace del supuesto de sentido común de que la tecnología cambia, moderniza y mejora la educación (...). La primera característica de la educomunicación como objeto socio-mediático es la confusión entre cultura y técnica. Así como en el caso anterior se presenta una relación consustancial entre código e institución o entre código y grupo, aquí se nos presenta la técnica como código. Por eso se habla de cultura digital, virtual, etc. (2013, p.9).

Otra afirmación tiene que ver con la posible relación entre técnica y lenguaje, en tanto se dice que la primera (referida específicamente a los medios de comunicación y a 
las nuevas tecnologías de la información) es generadora de "nuevos lenguajes". Ceballos y Marín (2003) señalan, por ejemplo, que debido a las nuevas tecnologías, surgen "nuevos lenguajes" que serán utilizados para la educación, a través de los medios de comunicación. Afirmación que aviva el debate, puesto que se le otorga al medio una facultad para crear lenguajes, es decir, se confunden sustancias expresivas con formas expresivas y formas de contenido.

No puede desconocerse que la preocupación por la relación expuesta (entre técnica y lenguaje) resulta interesante para varios autores, incluso desde fuera del campo. Autores como Leroi-Gourhan establecen vínculos de orden antropológico entre técnica y lenguaje. En un documento construido hace más de 50 años el autor usa en concepto de "gesto técnico"; puesto que asocia el desarrollo biológico del hombre desde sus orígenes hasta el homo sapiens (postura erguida, apertura del abanico cortical, liberación de la mano, liberación de la boca y capacidad simbólica), con el desarrollo técnico, en tanto elaboración de herramientas para facilitar la supervivencia, inicialmente, y luego con un sentido estético y ritual. La manera en que Leroi-Gourhan presenta sus argumentos hace que el lector piense en que para garantizar la supervivencia de la especie, el cuerpo de los antropoides sufrió varias modificaciones, pero solo gracias a su "cerebro súper especializado en la generalización" (Leroi-Gourhan, 1971, p. 120), pero sobre todo a su capacidad de simbolización, el hombre ha materializado sus pensamientos, otorgándole significado, uso e incluso forma, a todo aquello que encuentra en su ambiente. En lo referido a la comunicación, según los postulados de Leroi-Gourhan, su lugar está en la cultura, pero se llega a esta solo por el lenguaje. Es decir, aunque las condiciones biológicas para el lenguaje existan en toda la especie humana, la comunicación solo tiene lugar en la experiencia, en la cultura, en el encuentro con el otro.

El término "código" también es usado con frecuencia. Por ejemplo, Gabriel Kaplún (citado en Gall, 2005) habla de códigos experienciales, culturales, ideológicos, entre otros y en algunos casos suele asociarse el concepto de código con el de lengua. Para mayor precisión, respecto a los códigos, Eco afirma que "podríamos decir incluso que no es correcto afirmar que un código organice signos; parece ser que lo que hace un código es proporcionar las reglas para generar signos como ocurrencias concretas en el transcurso de la interacción comunicativa" (Eco, 2000, p.84). Dice también:

a) Un código establece la correlación de un plano de la expresión (en su aspecto puramente formal y sistemático) con un plano del contenido (en su aspecto puramente formal y sistemático); b) Una función semiótica establece la correlación entre un elemento abstracto del sistema de la expresión y un elemento abstracto del sistema del contenido; c) de ese modo, un código establece TIPOS generales, con lo que produce la regla que genera TOKENS o ESPECÍMENES concretos, es decir, aquellas entidades que se realizan en los procesos comunicativos y que comúnmente llamamos signos; d) ambos representan los elementos que preceden a la correlación semiótica (Eco, 2000, p.86)

Mayúsculas sostenidas en el texto original. 
Podría decirse entonces que el concepto de código se relaciona con la existencia de un conjunto de elementos que, para su combinación e interpretación, requieren el uso y conocimiento de unas reglas específicas; la lengua humana se correspondería con el concepto de código lingüístico.

En cuanto a la escritura, se profundiza poco, se exponen breves debates sobre la crisis del libro y se afirma que ya no es el único lugar en donde se localiza el saber. Pareciese que la discusión que despierta mayor interés se refiere a los medios de carácter audiovisual, cuya construcción es básicamente oral-icónica y no a aquellos que tienen un contenido fundamentalmente escrito. Lo que resulta coherente frente al proceso de modernización cultural en Colombia, puesto que el desarrollo de la cultura alfabética ha sido menor y reciente, comparado con el de la cultura oral-icónica (Narváez, 2012).

\section{Técnica y cultura}

Las discusiones sobre la técnica y la cultura no son cuestiones de ahora, menos en el campo educativo, solo que con la aparición de los medios masivos de comunicación e información, con la denominada convergencia digital y con las facilidades que estos tienen para que la información circule, se ha hecho repetitivo un discurso sobre las preocupaciones generadas en torno a la influencia de los medios en la cotidianidad de los sujetos y en las formas del ordenamiento de la vida social, así como en su potencial transformador de las realidades (tecnoutopía). Sin embargo, como se mencionó en el apartado anterior, se evidencian ciertas confusiones entre sustancia expresiva y sustancia del contenido.

Algunos autores presentan definiciones de los medios como técnica tales como: "instrumentos orientados a la producción tanto de bienes de capital como de mercancías en general" (Espitia y Valderrama, 2009 p.7). Otros los ven "más allá de los aparatos, en la perspectiva de la transformación cultural que éstos producen en las subjetividades, en el saber, en nuestra manera de pensarnos como colectivos" (Rueda y Quintana, 2004, p. 231) o "como estrategias de conocimiento y no como meros instrumentos de ilustración o difusión" (Martín-Barbero, 2003, p. 57).

En términos éticos, algunos hablan de tensiones entre tecnófilos y tecnófobos (Huergo y Fernández, 1999, p. 18), quiénes se unen a la idea de la necesidad de innovar en el aula y quiénes consideran que el poder ejercido por los medios es altamente persuasivo y manipulador, por lo tanto, los satanizan. Así mismo, se identifican los modelos a que normalmente responde el uso de los medios en la escuela, que son el informacional y el modelo pedagógico crítico (Huergo y Fernández, 1999 p. 62)

Se pueden identificar también varias maneras de asumir la técnica en el campo de la educomunicación en Colombia: a) como medios para mejorar los procesos de enseñanza-aprendizaje. Para algunos denominada tecnología educativa (en tanto se incluyen en el currículo para mejorar la enseñanza) y para otros informática educativa que "en buena medida le ha apuntado a la creación de propuestas mediadas por los últimos desarrollos tanto de software como de hardware, aunque la tendencia en las realizaciones prácticas 
ha estado más enfocada hacia el desarrollo tecnológico y de las habilidades y menos a la incorporación de la dimensión de la comunicación y de los contextos culturales" (Valderrama, 2000, p. XIV); b) como medios emisores/productores de los aprendizajes socialmente relevantes, como en el caso de internet, cuya existencia supone para algunos que la escuela empieza a hacerse innecesaria; c) como potenciadores de la creatividad en los actores escolares, puesto que le permiten al sujeto interactividad con el medio, producir contenidos y ponerlos en juego en su cotidianidad; d) como dinamizadores de redes mediadas por la tecnología, proceso que genera nuevas formas organizativas (por ejemplo, movilizaciones sociales agenciadas desde la participación en plataformas tecnológicas); e) como medios de democratización de la información versus la individualización del fenómeno comunicativo, en tanto algunas posturas enuncian que la manera en que hoy se construyen los medios facilita el acceso a la información y que esta hoy es conocimiento; y otros consideran que cada vez hay mayor individualización, por lo tanto hay mayor relación hombre-máquina que hombre-hombre. Lo comunicativo se reduce a un problema de medios tecnológicos (Cubides, 1998).

\section{El lugar del sujeto y las instituciones}

El "sujeto pedagógico" está siempre presente en el corpus de análisis. Aunque se menciona al estudiante y al docente como "actores" escolares, en el centro de las discusiones casi siempre está el primero de ellos. En principio, denominarlos actores supondría que representan e interpretan un rol específico, pero resulta que ellos son esos sujetos, no representaciones de ellos o de otros:

La idea del sujeto pedagógico concebido como 'alguien que aún no es' (sujeto aplazado), como un sujeto inacabado que llega a la institución escolar y debe ser moldeado, que no sabe el qué ni el para qué de su formación, como un sujeto lleno de carencias (no tiene experiencia, no posee conocimientos, no tiene moral, etc.), es cuestionada por la idea de un sujeto activo, lleno de experiencia, poseedor de saberes, diverso en su subjetividad, que tiene distintas percepciones espacio-temporales y entabla diferentes formas de relacionarse con el mundo a través de múltiples lenguajes diferentes del escrito o de la verbalización formalizada. (Espitia y Valderrama, 2009, p. 167).

Vale la pena mencionar que, al final de la cita, se cae nuevamente en la confusión sobre el lenguaje, pero independientemente de eso, se cuestiona el "ser" del sujeto actual, se afirma que es un sujeto social distorsionado [que] vive aislado y en función de estrategias individuales de supervivencia, "lo colectivo no hace parte de su existencia social, lo cual lo fragmenta y aísla" (Herrán, Martín-Barbero y Zambrano, 1999, p. 229). Desde este lugar, se propone que el maestro sea "capaz de reconocer la diversidad de formas de aprender, para ofrecérselas al estudiante y que este a su vez pueda reconocerse en algunas de ellas, como sujeto activo, capaz, productivo" (Moreno, 1999, p. 99). Así, educación y comunicación y valores y técnicas cobran valor puesto que se les otorga el rol de puente o lazo vinculante entre el individuo y el colectivo, entre prácticas individuales y prácticas culturales; reconociendo su dimensión histórica, política, su relación con el saber y con el lenguaje (Muñoz, 1996). 
En cuanto a las instituciones (la escuela, el Estado, la familia, los medios) todas son consideradas como espacios de socialización. Sin embargo, el foco de discusión se ubica en la escuela y en los medios. La institución escolar es vista desde dos orillas opuestas: desde la primera se le critica y se le endilgan responsabilidades por la crisis del mundo escolar, es señalada por desconocer la retórica de los medios, por evitar la vinculación del medio al espacio escolar, por desconocer las realidades circundantes, por haber sido uno de los escenarios de disciplinamiento social más fuertes y duraderos en la historia del país. Según lo expuesto por Huergo (2010, p. 73) la escuela puede entenderse como: espacio donde se hace visible la cultura, como microespacio social, como espacio de pugna por el sentido del mundo de la vida y de la experiencia subjetiva y como microesfera pública, donde se expresan los desencuentros, los conflictos y las zonas de fractura discursiva. Desde estos lugares, la escuela tiene un rol ético-político de doble vía, por su naturaleza busca conservar, pero a la vez abre caminos, abre horizontes de sentido y eso a veces se olvida.

De otro lado, en los trabajos se afirma que las transiciones y cambios a que se enfrenta la escuela tienen que ver en cierta medida con las dinámicas propias de los medios de comunicación. Desde este lugar se hace necesario que la institución escolar genere un proceso de reflexión sobre sí, sobre sus funciones, sus métodos, sus relaciones con la sociedad y con el conocimiento. Más aún, teniendo en cuenta lo disímil del discurso que transita en los espacios escolares (escuelas, estamentos) y entre los sujetos.

Para algunos, los medios son los culpables de que los jóvenes ya no lean. En las respuestas se plantea que hoy no solo se leen libros sino también productos audiovisuales y para ello no se necesita la escuela. Así, se afirma que esta debiera preocuparse por reconocer esas otras lecturas e incluirlas en sus prácticas cotidianas. Pareciese que el problema nuevamente se refiere al acceso, lectura y producción de contenidos mediáticos. No se reconoce la dimensión cultural del medio ni la evolución pobre o lenta, si se quiere, de la cultura alfabética en el país ni el desbordamiento de los medios de comunicación que generan un retorno sobre la oralidad:

Los medios y la escuela como instituciones especializadas, relativamente autónomas y con funciones diferenciada en la sociedad como portadoras de un cierto tipo de saber: por un lado, los medios, portadores de un tipo de saber más o menos común sobre el mundo cotidiano, o "saber socialmente relevante" y, por otro lado, la escuela, portadora de un saber estrictamente formalizado, codificado y especializado. (Narváez, 2004, p. 81).

En ese complejo escenario, los maestros se ven obligados a hacer elecciones y a moverse según sus intereses, sus competencias y las demandas del sistema a que pertenecen; y ante su dificultad (la dificultad cultural) para poner en convergencia cultura mediática y cultura escolar, la escuela es señalada como anquilosada, como estática, como reacia al cambio.

En ese sentido, y conforme a lo expresado antes sobre los códigos, el código empleado por los medios es distinto al usado por la escuela, de ahí que la tarea endilgada 
al maestro suele ser imposible. El primero no requiere especialización ni cualificación para su comprensión básica (su decodificación), su estructura hace parte de una lógica fundamentalmente oral-icónica, que corresponde con la manera primigenia de acceder a la cultura. La escuela, por su parte, emplea básicamente un código de orden alfabético, si se quiere artificial, por lo tanto requiere especialización, diseño, comprensión y aplicación de unas reglas específicas. Desde esta perspectiva, no serían dos códigos equiparables o intercambiables, lo que no evita que cualquier sujeto pueda adquirir el código, pero esto ya tiene implicaciones de otros órdenes, por ejemplo político y económico, en lo que se refiere a la producción y circulación de la información y el conocimiento.

\section{Conclusiones}

Aún existe una preocupación por el predominio de una mirada reduccionista sobre el campo de la educomunicación (escuela-medios). En los trabajos se hace un esfuerzo por reafirmar que el campo asume la comunicación con un enfoque diferente, sin embargo, la relación medios-escuela termina siendo el lugar común.

¿Cómo educar hoy? Aunque es innegable que existen significativas diferencias entre el hoy y el ayer de la escuela, se hace necesario preguntarse nuevamente cuáles son los discursos que transitan hoy en esta, cómo se dinamizan, cuál es el lugar del conocimiento científico en la escuela, cuál es el rol que los medios juegan en esos procesos y cómo estos llegan a la escuela:

La educomunicación no se agota en la perspectiva instrumental del uso didáctico de las tecnologías para la educación y en los esfuerzos para crear y mantener programas de educación para los medios (media education). Se trata, más allá, de una movilización de la sociedad para garantizar el derecho a la expresión, según la tradición de los movimientos populares latinoamericanos, rompiendo con 'la funcionalidad de la relación productor-receptor'. Nos referimos, esencialmente, a esfuerzos en la búsqueda de posibilidades para una gestión plenamente participativa y dialogal de los procesos comunicativos en los espacios educativos. Estas reflexiones deben propiciar en la escuela una automirada que le permita elaborar un discurso sobe ella misma que fluya hacia los medios [y hacia otros escenarios]. No debe esperar que sean los académicos, la iglesia, la empresa, las instituciones del Estado y los medios de comunicación los que propongan relatos sobre ella. La escuela necesita narrarse y circular su versión de sí misma de manera tal que sea capaz de dialogar con los relatos que desde otras instancias de la sociedad se proponen sobre ella. (Rojas y Valderrama, 2009 p. 9)

Sin embargo, apartados como el anterior, son de tipo prescriptivo y plantean el estado actual en el orden del deber ser y de la necesidad de ser.

Se evidencia también la necesidad de ampliar los estudios sobre la cultura mediática y la cultura escolar, así como la necesidad de analizar la cultura "digital" como parte de la cultura escolar (Narváez, 2004), entendiendo que de su comprensión depende en buena medida la manera en que se resignifica o asume el campo de la educomunicación. 
En cuanto a los medios, se reafirma la idea de formar a los públicos y a las audiencias para que sean sujetos activos, críticos, que de la mano de estos procesos formativos, se abran espacios de discusión, en donde los sujetos escolares tengan la posibilidad de problematizar sus percepciones sobre las tecnologías y el lugar de estas en la cotidianidad de la escuela, pero también de la vida misma, sin desconocer los tránsitos, traslapes y vacíos que han acompañado otras tecnologías del reciente pasado (Valderrama, 2000).

Autores como Huergo y Fernández plantean que:

Antes que preguntarnos por las vinculaciones operativas, tenemos que prestar atención a las provocaciones mutuas, a los modos en que, en la articulación, se refuerzan los procesos hegemónicos y los senderos posibles para andar resistencias. Antes que cómo usar los medios y las nuevas tecnologías (y cuáles usar), necesitamos comprender los sentidos del desorden cultural, de la cultura mediática, de los procesos de comunicación en la trama de la cultura y de los desarreglos que provocan en la educación escolar. Y antes que preguntarnos cómo educar para esa comunicación, indagar y desandar el «catecismo» instituido por la escolarización, retomando como alternativas las tradiciones residuales que nacen de la crítica a la educación tradicional y a la escolarización. Recién entonces trazar las diagonales de la topografía que permitan el reconocimiento de los tiempos largos y de los amplios espacios, desde los cuales se han marcado los cuerpos, las sensibilidades, los lazos sociales y las acciones políticas. Y que permitan también el reconocimiento de los sujetos de la creatividad, la autonomía y la imaginación instituyente. (1999, p. 78).

Como puede evidenciarse, la conceptualización y consolidación como campo científico aún es incipiente, hace falta claridad en la definición de los objetos de estudio, en los propósitos del campo científico, en últimas, sobre el lugar epistemológico en que se ubica la educomunicación. En los últimos años se han hecho algunos avances al respecto, asociados especialmente al lugar de la cultura en la relación entre comunicación y educación, pero serán objeto de otras publicaciones.

\section{Referencias}

Álvarez, A. (2003). Los medios de comunicación y la sociedad educadora. ¿Ya no es necesaria la escuela? Ciudad de México: Delfín.

Aparici, R. (Coord.) (2010). Educomunicación más allá del 2.0. (1ª ed.). Barcelona: Gedisa

Aranguren Díaz, F. (1996). La educación superior y las transformaciones de la comunicación. Revista Nómadas, (5).

Benavides, J. E. (1999). Grupo de familia: comunicación y educación, anfitriones y convidados para un compromiso que se construye. Signo y Pensamiento, 18(34).

Boutet, A. (1999). Comunicación y educación ambiental: Los retos de la participación en un contexto de 'guerra irregular'. El caso colombiano. Signo y Pensamiento, 18(34).

Brunner, J. (1996). ¿Fin o metamorfosis de la escuela? Revista Nómadas,(5).

Bustamante, B. (2006). Educación para la comunicación. Bogotá: Universidad Distrital. 
Bustamante Zamudio, G. (2003). La educación, ¿̇un asunto de medios? Revista Colombiana de Educación, (46), $116-134$.

Castellanos, A. (2005a). ¿Qué dicen y piensan los actores escolares sobre la comunicación?: Una versión de los discursos en la escuela. Revista Virtual Universidad Católica del Norte, (14), 1-10.

Castellanos, A. (2005b). Educación y comunicación. Reseña de una relación estratégica. Nómadas 5, 20-32.

Castiblanco, A. (1998). Comunicación educativa: una propuesta transdisciplinar. Revista de Ciencias Humanas, 5(18), 116-123.

Castiblanco, A. y Bedoya, O. (2002). Modos de ver: los sentidos de la comunicación educativa (19902002); una construcción desde la tesis de la maestría en comunicación educativa (1990-2002), Maestría en Comunicación Educativa, Universidad Tecnológica de Pereira. Pereira: Papiro.

Ceballos Sepúlveda, J. C. y Marín Ochoa, B. (2003). Comunicación, educación y ciudad. Medellín: Universidad Pontifica Bolivariana.

Charles Creel, M. (1999). Comunicación, educación y construcción de género. Signo y Pensamiento, 18(34),65-76.

Corporación Autónoma Regional del Alto Magdalena. (2002). Tejiendo para la vida: marco teórico de la comunicación y la educación ambiental. Cali: Corporación Autónoma Regional del Valle del Cauca.

Cruder, G. (1999). ¿Y las pantallas? De la normativa oficial al aula. Signo y Pensamiento, 18(34), 105-1 16.

Cubides, H. (1998). Otra mirada a la relación comunicación-educación. III Encuentro de investigación educación y desarrollo pedagógico en el distrito capital: un balance internacional. (417-423). Bogotá, Colombia: Instituto para la Investigación Educación y Desarrollo Pedagógico (IDEP).

Cubides, H. (2006). Travesías y sentidos. Memorias de maestros y maestras, Cátedra de Pedagogía Bogotá: una gran escuela. (249-255). Bogotá, Colombia: Santillana

Cubides, H. y Valderrama, C. (1996). Comunicación-educación: algunas propuestas investigativas. Revista Nómadas, (5). 120-138

Soares, I. (2009). Caminos de la educomunicación: utopías, confrontaciones, reconocimientos. Revista Nómadas, (30), 194-207.

Espitia Vásquez, U. y Valderrama, H. (2009). Hacia una apertura política del campo comunicacióneducación. Revista Nómadas, (30), 164-179.

Fuentes Navarro, R. (2003). Modelos y prácticas de educación: una perspectiva sociocultural. Revista Colombiana de Educación, (46), 26-39.

Fuenzalida Fernández, V. (1999). Televisión abierta para una cultura del protagonismo rural. Signo y Pensamiento, 18(34), 27-34.

Ghiso, A. (1999). Pedagogía y conflicto: pistas para deconstruir mitos y desarrollar propuestas de convivencia escolar. Signo y Pensamiento, 18(34), 45-58.

Gravis, A. (1999). Educación para los medios. Signo y Pensamiento, 18(34), 59-64.

Gutiérrez, F. (1995). Pedagogía de la comunicación en la educación popular. Bogotá: Magisterio. 
Hernández Sánchez, J. (2004). Encontrando sentidos: bases conceptuales y procedimientos técnicos en el desarrollo de estrategias integrales de comunicación educativa para la salud colectiva. Cali: Fundación para el Desarrollo de la Salud.

Hernández, C. A. (1996). Educación y comunicación: Pedagogía y cambio cultural. Revista Nómadas, (5). 68-86.

Herrán, M., Martín-Barbero, J. y Zambrano, M. (1999). Palimpsestos y recorridos de la comunicación en la educación. Bogotá: Universidad Pedagógica Nacional.

Herrera Solano, R. (1997). Teoría de la comunicación: la educación como sistema comunicativo. Bogotá, Colombia: Editorial Pontificia Universidad Javeriana.

Huergo, J. y Fernández, M. (1999). Cultura escolar, cultura mediática/intersecciones. Bogotá: Universidad Pedagógica Nacional.

López de la Roche, M. (1999). Procesos educativos y medios de comunicación: entre los deseos y las oportunidades. Signo y Pensamiento, 18(34),77-88.

Martín-Barbero, J. (1996). Heredando el futuro. Pensar la educación desde la comunicación. Revista Nómadas, (5). 20-31.

Martín-Barbero, J. (1999). Retos culturales: de la comunicación a la educación. Ed. Cátedra Unesco de Comunicación Social 1996 - 1998, Pontificia Universidad Javeriana. Bogotá.

Martín-Barbero, J (2002). La educación desde la comunicación. Bogotá: Norma.

Mejía Jiménez, M. (1996). Educación popular hoy: entre su refundamentación o su disolución. Revista Nómadas, (5).115-122.

Mejía, M. (2011). La(s) escuela(s) en la(s) globalización(es) II. Entre el uso técnico instrumental y las educomunicaciones. Bogotá: Desde abajo.

Moreno Angarita, M. (1999). El aprendizaje: motor para la tríada más poderosa del XXI. Información, comunicación y tecnología. Signo y Pensamiento, 18(34), 89-104.

Muñoz González, G. (1996). El sujeto de la educación. Revista Nómadas, (5). 146-158

Narváez Montoya, A. (2004). Cultura mediática y educación formal: un punto de vista comunicacional. Revista Colombiana de Educación, (46), 80-115.

Ojeda Contreras, S. (2002). Cartilla de medios de comunicación y educación. Bogotá: Universidad Distrital Francisco José de Caldas.

Oróstegui Arenas, B. (1991). Comunicación y educación en salud. Bucaramanga: Universidad Industrial de Santander.

Orozco Gómez, G. (1996). Educación, medios de difusión y generación de conocimiento: hacia una pedagogía crítica de la representación. Revista Nómadas, (5). 159 168

Peña Rodríguez, F. (1998). La comunicación como un acto pedagógico. Revista Intervisiones, 9(2), 35-37.

Ramírez, L. y López, M. (2009). Comunicación y educación incluyentes: estrategias para la incidencia de la población discapacitada en políticas públicas. Bogotá, Colombia: Fundación Foro Nacional por Colombia. 
Rodríguez Uribe, H. (2008). Medios de comunicación y educación. La Perspectiva Radial. Hallazgos, 9(18), 161-173.

Rodríguez, J. (2005). Comunicación y escuela: orientaciones para la incorporación, usos y apropiación de los medios de comunicación en las instituciones educativas de Bogotá. Revista Colombiana de Educación, (49), 215-219.

Rojas, S. y Valderrama, C. (2009). La investigación sobre medios y educación en Colombia. Cuadernos de Psicopedagogía, (6), 9-24.

Uribe Camargo, A. y Hederich M. (2007). El estilo de comunicación y su presencia en el aula de clase. Folios, segunda época, (26), 3-12.

Valderrama, C. (2004). Discursos y dinámicas escolares. Revista Colombiana de Educación, 46. doi. org/10.17227/01203916.5504.

Valderrama, C. (Dir.). (2000). Comunicación-Educación. Coordenadas, abordajes y travesías. Bogotá: Siglo del Hombre Editores.

Varela Realpe, F. Fernández, A., Romero, y Arce Cabrera, A. (2010). Mirando cómo miramos: una propuesta desde la comunicación y la educación para multiplicar miradas. Cali: Universidad Santiago de Cali.

Vargas Guillén, G y Rueda Ortiz, R. (1996). La pedagogía ante la tecnología como estructura del mundo de la vida. Revista Nómadas, (5).

Vásquez Rodríguez, F. (1999). Avatares: analogías en búsqueda de la comprensión del ser maestro. Signo y Pensamiento, 18(34), 117 - 124.

Wiesner, C., Donoso, I., Tovar, S., Cortés, C. y Nieto, J. (2007). Modelo de comunicación educativa para el control del cáncer en Colombia. Bogotá: Editorial Instituto Nacional de Cancerología. 